\title{
Digital tools for delivery of dementia education for healthcare providers: a systematic review
}

Article

Accepted Version

Scerbe, A., O'Connell, M. E., Astell, A., Morgan, D., Kosteniuk, J. and DesRoches, A. (2019) Digital tools for delivery of dementia education for healthcare providers: a systematic review. Educational Gerontology, 45 (11). pp. 681-699. ISSN 1521-0472 doi:

https://doi.org/10.1080/03601277.2019.1687149 Available at https://centaur.reading.ac.uk/87138/

It is advisable to refer to the publisher's version if you intend to cite from the work. See Guidance on citing.

To link to this article DOI: http://dx.doi.org/10.1080/03601277.2019.1687149

Publisher: Taylor \& Francis

All outputs in CentAUR are protected by Intellectual Property Rights law, including copyright law. Copyright and IPR is retained by the creators or other copyright holders. Terms and conditions for use of this material are defined in the End User Agreement. 


\section{CentAUR}

Central Archive at the University of Reading

Reading's research outputs online 


\title{
Digital Tools for Delivery of Dementia Education for Healthcare Providers:
}

\author{
A Systematic Review \\ Scerbe, A., O’Connell, M. E., Astell, A., Morgan, D., Kosteniuk, J., DesRoches, A.
}

Author Note

Andrea Scerbe, Department of Psychology, University of Saskatchewan; Megan E., O’Connell, Department of Psychology, University of Saskatchewan; Arlene Astell, Department of Occupational Sciences \& Occupational Therapy and Department of Psychiatry, University of Toronto; KITE, University Health Network; Debra Morgan, College of Medicine, University of Saskatchewan; Andrea DesRoches Department of Psychology, University of Saskatchewan.

Trainee funding was provided by the Canadian Consortium on Neurodegeneration in Aging (CCNA). CCNA is supported by a grant from the Canadian Institutes of Health Research with funding from several partners including the Saskatchewan Health Research Foundation.

Corresponding author: Megan E. O’Connell, Department of Psychology, University of Saskatchewan, 9 Campus Drive, Saskatoon SK S7N 5A5. E-mail: megan.oconnell@usask.ca Disclosure statement: No potential conflict of interest was reported by the authors. 


\begin{abstract}
Continuing education on dementia for healthcare providers has been shown to have positive effects on diagnostic confidence, knowledge, and care management. Technological approaches to educational delivery have been found to have comparable effects in terms of quality and efficacy. The purpose of the systematic review was to compose and present an evidence base for technology-delivered dementia education for healthcare providers. The review used PRISMA guidelines and Cochrane methods focusing on studies with a pre- and post-intervention evaluation. Technology-based delivery of dementia education was broadly defined as any technology-based medium delivered in real time or asynchronously. Ten studies were identified and analyzed using content analysis. The review revealed positive outcomes post-intervention, for dementia knowledge, readiness to change, receptiveness to training, communication skills, and self-efficacy. Studies were rated as medium to high quality on a scale for measurement of published data in research, and there was generally an unknown risk of bias due to a lack of a control group in most studies $(N=7)$. The findings revealed benefits of digitally-based, asynchronous continuing education for healthcare providers, which allow schedule flexibility and the ability to deliver remotely. Findings also revealed benefits of presentations using a variety of interactive educational materials via videos, voice recordings, textual medium and online discussion groups. Suggestions for intervention improvements include tailoring training for the specific needs and knowledge levels of healthcare practitioners and using validated scales to measure outcomes.
\end{abstract}

Keywords: dementia, education, technology, systematic review, Cochrane review 


\section{Digital Tools for Delivery of Dementia Education for Healthcare Providers: A Systematic Review}

Dementia exigency is a world predicament (WHO, 2012 Alzheimer Society of Canada, 2010) that has unique impact in rural settings (Canadian Academy of Health Sciences, 2019). Delivery of care and supports is contingent on timely diagnosis (Innes, Szmczynska, \& Stark, 2014; Di Gregorio, Ferguson, \& Wiersma, 2015), but inadequate dementia knowledge increases the potential for missed diagnoses (Coogle, Head, Parham, \& Zeman, 2004). Once diagnosed, healthcare providers require knowledge of psychosocial and physical aspects of care (Coogle et al., 2004). A general lack of dementia training and education is reported by healthcare providers (Adler, Lawrence, Ounpraseuth, \& Asghar-Ali, 2015; Barrett et al., 1997; Bryans, Keady, Turner, \& Wilcock, 2003; Cary, 2009; Gandesha, 2012; Hallberg et al., 2016; Manthorpe, Iliffe, \& Eden, 2003). Lack of dementia education impacts quality of services (Broughton et al., 2011), and hinders healthcare providers' abilities to provide care (Adler et al., 2015; Broughton et al., 2011; Cary, 2009; Gandesha, 2012; Hallberg et al., 2016). Dementia education can improve knowledge (Arnautovska, Roleda, Jackson, \& Pachana, 2016; Boise et al., 1999; Broughton et al., 2011; Cody, Beck, Shue, \& Pope, 2002; Eggenberger, Heimerl \& Bennet, 2013; Elliot et al., 2012; Fossey et al., 2014; Gandesha, 2012; Harvey, Hovarth, Levine, \& Volicer, 2006; Mitchell, Meader, \& Pentzek, 2011; Spector, Revolta, \& Orrell, 2016), clinical practice (Brody \& Galvin, 2013; Spector, Orrell, Goyder, 2013; Zients at al., 2007; Galvin, Meuser, Boise, \& Connell, 2011), increase confidence and skill (Boise et al., 1999; Broughton et al., 2011; Gandesha, 2012), encourage better coordinated care (Buhler et al., 2011), increase adherence to best practice guidelines (Galvin, Meuser, Boise, \& Connell, 2011), improve attitudes (Manthorpe et al., 2003; 
Sizemore, Vicioso, Lothrop, \& Rubin, 1998), and reduce diagnostic uncertainty (Broughton et al., 2011; Harvey, et al., 2006; Rokstad et al., 2016).

Digital methods for education have the added advantage of remote, asynchronous delivery (Broughton et al., 2011; Harvey et al., 2006; Ruiz, Smith, van Zuilen, Williams, \& Mintzer, 2006; Waldorff, Siersma, Nielsen, Steenstrup, \& Bro, 2009) which offers particular benefits for rural and remote healthcare providers facing additional challenges such as a lack of access to specialized dementia services and continuing education (Kosteniuk et al., 2016). The present paper is a review of digital methods for dementia education. Importantly, the present review differs from earlier reviews (Alushi et al., 2015; Beeber et al., 2010; Boots et al., 2013; Brody et al., 2013; Eggenberger et al., 2013; Elliot et al., 2012; Fossey et al., 2014; Kuske et al., 2007; Raymond et al., 2014; Spector et al., 2013; Surr et al., 2017; Zients et al., 2007), in two ways: 1) focus on broad range of settings, healthcare professions, and types of digitally-based dementia education interventions; and 2) focus on studies with quantitative measures of a preintervention (baseline measure) and a post-intervention measure of change on outcomes. The current review addressed the following questions: 1) What learning technologies, online resources, and digital education tools on dementia are available? 2) At whom are the tools aimed (e.g., relevant characteristics of targeted healthcare providers)? 3) How many of the tools are for learning about dementia (e.g., causes, types and symptoms) versus dementia management or other purposes? 4) How are the digital education tools evaluated? 5) What are the measured, intended or unintended outcomes? Finally, this review also serves to establish a summary of existing digitally-based modes of dementia education, which can be used to design future digitally-delivered, asynchronous modes of dementia education for healthcare providers.

\section{Method}


Preferred Reporting Items for Systematic Reviews and Meta-Analyses (PRISMA) recommendations (Moher, Liberati, Tetzlaf, \& Altman, 2009), and Cochrane guidelines for systematic reviews and meta-synthesis (Moseley, Elkins, Herbert, Maher, \& Sherrington 2009; Jørgensen, Hilden, \& Gøtzsche, 2006) were employed. Studies were identified by searching electronic databases and reviewing the citations of articles selected for inclusion in the review (Figure 1) using Covidence, an online systematic review management software (Veritas Health Innovation, 2017). The search strategy process followed the Cochrane guidelines (Moseley, Elkins, Herbert, Maher, \& Sherrington 2009) and the list of databases included PsychINFO, MEDLINE, Cumulative Index of Nursing and Allied Health Literature (CINAHL), Sociological Abstract, SocINDEX, AgeLine, Anthropology plus, and Embase.

Two reviewers independently screened and made decisions for inclusion/exclusion, reasons for exclusion were recorded in a PRISMA diagram (see Table 1 and Table 2). Disagreement regarding inclusion was resolved via verbal deliberation, with a third individual available to arbitrate. Data extraction was performed in duplicate by the same two reviewers, with an adapted and customized data extraction form adapted from the Cochrane Collaboration (Higgins \& Green, 2011). A meta-analysis was not possible due to the heterogeneity in outcomes, and lack of a control group in many of the studies. The results of the studies were qualitatively examined using content analysis to formulate categories or over-arching themes and to derive answers to the five research questions listed above.

\section{Inclusion Criteria}

Studies included in the review were published in English, and included at least one technology or digital tool that was used to convey dementia education targeted to healthcare professionals such as physicians, nurses, care workers, care aides, or personal support workers. 
The digital tools included e-learning and other electronic media, via computer networks, teleconferencing networks or telephones. Included interventions had a measure of pre- and postoutcome findings and offered structured education defined as the delivery of predetermined dementia information.

\section{Exclusion Criteria}

Excluded studies were other systematic reviews, studies lacking an evaluative component, studies that used a satisfaction measure as the sole measure of the intervention effect, studies lacking structured education, studies lacking technology, studies targeting types of recipients other than healthcare professionals, studies lacking an educational dementia component, and studies where the educational component contained dementia in addition to other medical education, but where findings included a compounded analysis (e.g., the effect of the intervention on dementia knowledge could not be separated from the overall effects).

\section{Risk of Bias and Study Quality}

The risk of bias was assessed in duplicate by two reviewers using a set of criteria adapted from Cochrane methods for risk of bias evaluations (Higgins \& Green, 2011). The risk of bias was rated independently by each reviewer for each study as low, medium, or high risk, and deliberated to achieve $100 \%$ agreement. The included studies were also subject to a quality review, which was performed by adapting checklists from the Critical Appraisal Skills Programme (CASP, 2014). One set of criteria was developed for evaluating studies of randomized controlled trials and one set was developed for studies with a single group evaluated pre- and post-intervention (see Tables 1 and 2).

The range of possible quality CASP scores for studies using non-randomized controlled trials (non-RCT studies) ranged from 0 to 18 , where low quality studies ranged from 1 to 6 , 
medium quality studies ranged from 7 to 12 , and high-quality studies ranged from 13 to 18 . The range of possible quality CASP scores for randomized controlled studies (RCT studies), utilizing a single group who received the intervention, ranged from 0 to 21 , where low quality studies ranged from 1 to 7 , medium quality studies ranged from 7 to 15 , and high-quality studies ranged from 16 to 21 . The quality criteria were not used to determine study exclusion, but rather to provide a description of study quality. Studies which were deemed 'high quality' met the majority of the quality criteria. Studies which were deemed in the 'medium quality' range met an acceptable level of quality, and studies which were deemed in the 'low quality' range did not meet a sufficient number of quality criteria. The evaluation of study quality was performed independently by two reviewers with a third individual available to arbitrate.

\section{Results}

Ten studies were included in the review (see Table 3). Three studies were a randomized controlled trial (RCT) (Broughton et al., 2011; Downs et al., 2006; Rosen et al., 2002), and one study included a case-controlled study (Luconi et al., 2008). Of these ten studies, five included an education program derived from a theoretical model (Chao et al., 2016; Hobday et al., 2017; Irvine et al., 2012; Luconi et al., 2011; Pleasant et al., 2017). Theoretical models included learning models such as the Adult Learning Theory (Knowles, 1996), the Four-Stage Theory of Physician's Learning (Slotnick, 2001), and the Clinical Reasoning Model (Barrows \& Feltovich, 1987). Other models were derived from larger theories in psychology, such as the Social Cognitive Learning Theory (Bandura, 1977) and the Expanded Theory of Reasoned Action (Fishbein \& Ajzen, 1975). The remaining studies employed concepts derived from the $C A R E S^{T M}$ Dementia-Friendly Hospital Learning Principles (Merkt, Weigand, Heier, \& Schwan, 2011) and CARES $^{T M}$ Dementia Basics Program principles (Hobday, Savik, Smith, \& Gaugler, 2010). From 
a total number of participants $(N=760)$ study-based sample sizes ranged from $n=8$ to $n=113$, of which $38 \%$ to $100 \%$ were female. Study attrition ranged from 1 to 11 participants, but four studies (Banks et al., 2014; Hobday et al., 2017; Luconi et al., 2008; Ruiz et al., 2006) did not report their attrition rates. The intervention duration ranged from a single 2-hour long session to a 12-month period with asynchronous completion of computer modules. Half of studies were conducted in United States (5 studies; see Table 4) (Hobday et al., 2017; Irvine et al., 2012; Rosen et al., 2002; Ruiz et al., 2006; Pleasant et al., 2017). The setting of interventions included long-term care/nursing homes (4 studies) (Chao et al., 2016; Broughton et al., 2011; Irvine et al., 2012; Rosen et al., 2002), secondary education or professional settings (2 studies) (Ruiz et al., 2006; Luconi et al., 2008), general practices/hospitals (3 studies) (Banks et al., 2014; Downs et al., 2006; Hobday et al., 2017; Pleasant et al., 2017; see Table 4). The geographic location of studies was largely unreported and unknown (in 9 studies), with only one study reporting a rural location (Luconi et al., 2008).

\section{Risk of Bias}

Risk of bias ratings for most studies was unknown due to the study design (see Table 5; e.g., single treatment group without controls or random allocation). For RCT studies (3 studies) (Broughton et al., 2011; Downs et al., 2006; Rosen et al., 2002), random allocation was presumed, but not always clearly reported. Only one RCT reported how the random allocation was performed (Downs et al., 2006). Concealment of allocation, blinding of participants, and blinding of assessment outcomes procedures were not always possible given the methods used by the majority of the included studies (either absence or presence of dementia education: 7 studies) (Banks et al., 2014; Chao et al., 2016; Hobday et al., 2017; Luconi et al., 2008; Irvine et al., 2012; Pleasant et al., 2017; Ruiz et al., 2006). In terms of data reporting five studies reported 
only significant outcomes (Banks et al., 2014; Chao et al., 2016; Downs et al., 2006; Pleasant et al., 2017; Ruiz et al., 2006), and half of the studies reported all outcomes (Broughton et al., 2006; Hobday et al., 2017; Irvine et al., 2012; Luconi et al., 2008; Rosen et al., 2002).

\section{Study Quality}

The three RCT studies (Broughton et al., 2011; Downs et al., 2006; Rosen et al., 2002), were evaluated using the CASP quality criteria for RCTs, and the single treatment group studies (non-RCTs) (7 studies) (Banks et al., 2014; Chao et al., 2016; Hobday et al., 2017; Luconi et al., 2008; Irvine et al., 2012; Pleasant et al., 2017; Ruiz et al., 2006) were evaluated using CASP quality criteria for non-RCT studies (see Figure 2 and Figure 3). The RCT studies had high quality ratings overall, and demonstrated meticulousness in reporting, including descriptions of the population of interest, and unbiased approaches to reporting of findings. However, one RCT study did not report on the blinding of participants (Broughton et al., 2011). The quality of nonRCT studies ranged from medium (in 1 study) (Banks et al.) to high range (in the remaining 5 studies). One aspect affecting most of the non-RCT studies, thus lowering their overall quality from high to medium range, was a lack of standardized scales to measure outcomes (in 5 of the non-RCT studies) (Banks et al., 2014; Hobday et al., 2017; Irvine et al., 2012; Pleasant et al., 2017; Ruiz et al., 2006; ) and a tendency to use non-validated scales (in 6 studies) (Banks et al., 2014; Downs et al., 2006; Hobday et al., 2017; Luconi et al., 2008; Irvine et al., 2012; Ruiz et al., 2006). The breakdown of the average quality ratings for individual quality criteria for RCT and non-RCT studies can be found in Figures 2 and 3, respectively.

\section{Types of Healthcare Professionals Included in Interventions}

Nurses were the most common type of healthcare professionals, and were included in half of the interventions (5 studies) (Banks et al., 2014; Broughton et al., 2011; Chao et al., 2016; 
Hobday, Gaugler, \& Mittelman, 2017; Rosen et al., 2002; Ruiz et al., 2006). Registered nurses (RNs) received most of their training remotely (Banks et al., 2014; Broughton et al., 2011; Chao et al., 2016; Rosen et al., 2002), and licensed practical nurses (LPNs) received their training via a computer in a classroom setting (Ruiz et al., 2006). Other healthcare professionals were managers and directors of a long-term care facility (Irvine et al., 2012). Two studies included family physicians (Banks et al., 2014; Luconi, 2008). One study focused solely on physician education (Luconi, 2008), and one study included a physician in an intervention targeted to diverse health professionals (Banks et al., 2014). The remaining professions represented included recreational activity officers (Banks et al., 2014; Broughton et al., 2011), dietitians, occupational therapists, physiotherapists, speech and language pathologists, managers (Banks et al., 2014), non-direct care staff in long-term care (Irvine et al., 2012), and other formal carers of individuals with dementia, such as volunteers with some training in care provision and who were in regular contact with patients (Pleasant et al., 2017). Recruitment of participants occurred in nursing home settings (Broughton et al., 2011), long-term care settings (Irvine et al., 2012), educational settings (Rosen et al., 2002; Ruiz et al., 2006), and mixed settings including a combination of health centers and hospitals (Chao et al., 2016; Downs et al., 2006), and via public message announcements (Chao et al., 2016) and existing organization-networks, and online recruitment strategies (Banks et al., 2014; Luconi, 2008; Pleasant et al., 2017),

\section{Learning Methods and Types of Educational Tools}

The digital modes of learning frequently featured more than one medium to convey knowledge, including video, audio-narration, asynchronous computer-based modules with educational content, graphics, and some interactive content (Banks et al., 2014; Chao et al., 2016; Hobday et al., 2017; Irvine et al., 2012; Luconi, 2008; Rosen et al., 2002) (see Table 6). 
Many studies included multi-feature components of learning, including videos. For example, Banks et al. (2014) used educational video resources; Hobday and colleagues (2017) used unscripted video resources that featured scenarios with real patients and interviews with experts; Irvine and colleagues (2012) used video-modeling vignettes to emphasize case scenarios and interviews with experts; and Rosen and colleagues (2002) used interactive video modules, specially designed in a news-documentary format with exercises and questions relating to the visual content.

Many of the studies also supplemented their online learning content with other mediums such as audio narration (Hobday et al., 2017; Irvine et al., 2012), online group discussion forums (Banks et al., 2014; Luconi, 2008), and quizzes with automatic feedback (Luconi, 2008). A study by Peasant and colleagues (2017), relied mostly on presenting textual information (Pleasant et al., 2017). Additional learning features were assigned readings (Banks et al., 2014), interactive text entry, graphics, case studies (Hobday et al., 2017), and email reminders (Luconi, 2008). Two studies used designated platforms to deliver educational content; for example, one study used online education available via a work-site home page (Irvine et al., 2012), another study (Ruiz et al., 20016) used computer-based learning modules, accessible only via a computer-testing laboratory of an educational institution, and another study used modules available via an online platform licensed to the institution (Luconi, 2008).

Two studies did not convey their education online; for example, Downs and colleagues (2006) used an electronic tutorial with an indexing system embedded in existing medical records software, which produced prompts and provided real-time learning about diagnosis and management of dementia. Lastly, two studies included a required in-person attendance component. Banks and colleagues (2014) featured blended learning where participants accessed, 
read, and watched e-learning resources, and communicated in an online forum prior to attending five half-day lectures. In their study, Chao and colleagues (2016) included a portion of learning delivered in a classroom and a portion of learning delivered via structured internet-based learning.

\section{Focus of Educational Content}

The broad topics of education included categories such as dementia screening and assessment (Pleasant et al., 2017), clinical decision making (Downs et al., 2006), individualized care (Hobday et al., 2017; Pleasant et al., 2017; Ruiz et al., 2006), care management (Luconi, 2008; Rosen et al., 2002), enhancing skill and confidence (Irvine et al., 2012; Luconi, 2008), enhancing communication abilities (Irvine et al., 2012; Rosen et al., 2002), coping (Rosen et al., 2002), attitudes toward dementia care (Ruiz et al., 2006), vulnerability and ethical issues (Pleasant et al., 2017; Rosen et al., 2002), and end of life care and discharge (Pleasant et al., 2017). Interventions also targeted larger groups of healthcare professions with a varying skill levels, and focused on developing materials with $6^{\text {th }}$ to $8^{\text {th }}$ grade reading levels (Hobday et al., 2017; Irvine et al., 2012; Rosen et al., 2002).

The learning materials included content about memory profiles in dementia (Banks et al., 2014; Broughton et al., 2011; Rosen et al., 2002; Ruiz et al., 2006), clinical reasoning (Downs et al., 2006), dementia diagnosis (Luconi, 2008; Pleasant et al., 2017), patient care strategies (Broughton et al., 2011; Downs et al., 2006; Hobday et al., 2017; Irvine et al., 2012; Luconi, 2008; Pleasant et al., 2017; Rosen et al., 2002; Ruiz et al., 2006), managing behavioral and psychological aspects of dementia (Chao et al., 2016), changing attitudes toward dementia care (Ruiz et al., 2006), working with vulnerable populations (Pleasant et al., 2017; Rosen et al., 
2002), and communication strategies (Broughton et al., 2011; Chao et al., 2016; Irvine et al. , 2012; Rosen et al., 2002).

\section{Evaluation of Digital Educational Tools}

The studies generally focused on evaluating dementia knowledge (Banks et al., 2014; Hobday et al., 2017; Ruiz et al., 2006; Pleasant et al., 2017; Rosen et al., 2002) and included scales developed by study authors, some of which were validated (Hobday et al., 2017, Rosen et al., 2002, Ruiz et al., 2006). For example, Hobday and colleagues (2017), Rosen and colleagues (2002), and Ruiz and colleagues (2006) did not include scale validation, and measures used by Banks and colleagues (2014) (Approaches to Dementia Scale: ADS) and Pleasant et al. (2017) (Dementia Knowledge Questionnaire: DKQ) included scale validation (see Table 7). Studies also focused on satisfaction with care giving. For example, Broughton and colleagues (2011) used two types of scales (Positive Aspects of Care Giving Questionnaire: PAC, and Caregiver Satisfaction; both validated scales with high convergent validity and internal consistency reliability), plus patient communication skills via self-reported surveys. Chao and colleagues (2016) used four validated scales (Communication Knowledge Scale: CKS-C, Communication Skills Attitudes Scale: CSAS-C, Patients' Receptive and Expressive Ability: PREAS, and Revised memory and Behavior Problems Checklist: CSDD-C; all scales were Chinese versions), all with evidence of high reliability and validity.

Studies also measured self-efficacy and competence in care, but varied in the quality of their measurement. Banks and colleagues (2014) and Ruiz and colleagues (2006) used nonvalidated scales developed for the purpose of assessing their respective program materials. Similarly, Irvine and colleagues (2012) used a measure of situational self-efficacy in response to a video-situation test which was specially developed and validated for intervention purposes. 
Pleasant and colleagues (2017) used a validated scale (Sense of Competence in Dementia Scale: SCIDS) to assess participant competency, and Irvine and colleagues (2012) used the video situation test with validated measures to assess attitudes toward dementia care and behavioral intentions with regards to behavior change. The study by Luconi (2008) measured only reaction to training with the Barometer scale (non-validated scale, developed to measure readiness to learn), as well as confirmation of new learned knowledge with existing knowledge using the Participant Reaction Questionnaire (PRQ-I, also not validated). Lastly, a study by Downs and colleagues (2006) measured dementia detection rates and concordance with guidelines by directly extracting tracked information from patient health records, and using coded checklists for diagnosis concordance and management concordance.

\section{Outcomes}

Study outcomes corresponded to the measures developed or chosen for specific hypothesized effects. Four studies (Downs et al., 2006; Rosen et al., 2002; Pleasant et al., 2017; Ruiz et al., 2006) evaluated dementia knowledge, and all four found significant improvement on measures of dementia knowledge (see Table 7). Other aspects of dementia knowledge that were measured included dementia care, dementia care management knowledge, and change in practice (Downs et al., 2006; Hobday et al., 2017). Hobday and colleagues (2017) found a significant difference in dementia care knowledge, while Downs and colleagues (2006) (using a checklist reflecting dementia practice) did not find a significant change in practice.

Two studies (Banks et al., 2014; Broughton et al., 2011) addressed knowledge of care strategies in their outcomes. These studies used measures such as the Approaches to Dementia Scale, Positive Aspects of Care giving, and caregiver satisfaction to measure knowledge of care, all of which indicated a significant positive change in knowledge relating to dementia care 
strategies. A study by Chao and colleagues (2016) examined communication skills with validated, adapted and translated scales (adapted for Chinese speakers), all of which indicated significant findings, with the exception of a scale indicating a lack of change in communicationrelated attitudes (Communication Skills Attitudes Scale-Chinese Version: CSAS-C).

Four studies (Irvine et al., 2012; Banks et al., 2014; Pleasant et al., 2017; Ruiz et al., 2006), measured a change in reported self-efficacy and found significant changes. Lastly, a study by Irvine and colleagues (2012) measured change in attitudes toward dementia care and found significant results, indicating that the intervention was effective in enhancing more positive attitudes toward dementia care.

\section{Discussion}

While previous systematic reviews focused on satisfaction-based evaluations of educational interventions (Surr et al., 2017), specific work settings (Beeber et al., 2010; Kuske et al., 2007), healthcare populations (Alushi et al., 2015), communication (Eggenberger et al., 2013), approaches (Fossey et al., 2014), organizational outcomes (Elliot et al., 2012), or defined aspects/outcomes of dementia training, such as management (Brody et al., 2013), the present review focused only on digital modes of dementia education for healthcare professions which included pre- and post-intervention measures. Ten studies describing technology-based dementia education to healthcare professionals with pre- and post-education comparisons were identified. Despite a variability in educational mediums and educational delivery, and although recent research indicates that interactive components have better effects on learning receptiveness (Surr et al., 2017), all of the studies demonstrated positive changes in outcomes. Additionally, the studies featured an array of professionals, working in a wide variety of work environments, using adaptable and flexible technologically-delivered modes of education. Future technology-based 
dementia educational interventions for healthcare providers would greatly benefit from the inclusion of a control group, such as in an RCT design, and the inclusion of validated scales. Such additions could improve the quality and generalizability of study findings.

While the risk of bias assessment could not be completed due to a lack of a control condition in most studies, the CASP quality rating of literature indicated that the authors were measuring the intended constructs in their interventions. A meta-analysis of the findings was also not possible due to the heterogeneity in measurement tools and outcomes. Nevertheless, all studies found at least some positive impact of the interventions on outcomes, regardless of the mode of intervention, materials used in the intervention, or validation of scales, indicating that technology-based dementia education did have a positive impact on learning for healthcare providers.

\section{Limitations/Strengths/Recommendations}

A limitation of this review is that it focused only on studies available in English. Due to a wide variety of measures/outcomes, a meta-analysis also was not possible, and due to the same heterogeneity, most studies had an unknown risk of bias. Studies with this type of intervention, targeting healthcare providers that feature a control group or an RCT design, could improve the ability to perform bias ratings, and thus provide a better evaluation of study quality. Additional benefits of an RCT design are a greater confidence in the results, and an assurance that a meaningful change occurred.

Due to the heterogeneous nature of interventions and desired outcomes, it was difficult to distinguish which types of approaches were more efficacious than others. However, it is noteworthy that all of the interventions, regardless of their design, duration, type of digital tool, or content of materials, noted a positive change in outcomes. Videos featuring modeling, case- 
based scenarios, and interviews with experts were deemed beneficial. Other features deemed useful by participants were email reminders to complete modules, a calendar function, and available technical support (Luconi, 2008). Future interventions should focus on including a variety of interactive, textual and graphic materials. Interventions designed to retain attention and keep participants stimulated are also likely to ensure continued engagement. Periodic testing of the learned materials may also be useful for rehearsing and encoding learned information, and can favorably affect not only the intended outcomes, but also long-term knowledge retention (Karpicke \& Smith, 2012).

When developing an intervention for a specific healthcare population, it may be advantageous for researchers to consider the level of knowledge, skill, or previous training of such populations. By building on existing knowledge, skills, and needs of healthcare practitioners, one can ensure that an intervention will ameliorate knowledge gaps and increase receptiveness. Additionally, the choice of content delivery may depend on intended outcomes. For example, if a successful outcome is improving the knowledge of a memory profile in dementia, then the materials in the intervention should focus on conveying and assessing such knowledge. Another useful feature of a technology-based, asynchronous dementia education is content development, based on healthcare provider input, need, or skill-level as indicated by performance on a pre-intervention measure. As noted in previous research by Degryse and colleagues (2009) and Scott and colleagues (2015), interventions that are suited to the unique needs of specific healthcare practitioner groups are more likely to have a positive effect on knowledge acquisition and behavior change.

All of the studies in the review used scales to measure outcomes; however, some of the studies used newly developed scales (Hobday et al., 2017; Irvine et al., 2012; Rosen et al., 2002), 
and not all of the scales were validated (Hobday et al., 2017; Rosen et al., 2002; Ruiz et al., 2006). Researchers recommend using validated scales to help ensure that any obtained differences are not present due to measurement bias (Arribas-Marín, Hernández-Franco, \& Plumed-Moreno, 2017; Wood, Garb, Lilienfeld, \& Nezworski, 2002). Nevertheless, many studies did not employ this approach. Therefore, increased confidence in the intervention outcomes could be obtained with the use of validated scales. Last but not least, future researchers may consider administering education based on a learning model or a theory. While this approach does not guarantee significant or observable changes, a theory will help to determine the delivery of information and potential outcomes, and can assist in determining appropriate measures.

\section{Conclusion}

The review uncovered compelling confirmation of effectiveness of various digitallyconveyed dementia education modes for healthcare providers. The review also revealed a variety of interventions, including computer-based and video-based learning, targeting a large array of health professionals, featuring materials developed to suit a broad range of skill levels and knowledge. The most common type of intervention occurred via computer, and through the completion of learning modules. The content of interventions focused on a variety of topics including dementia diagnosis (Downs et al., 2006; Pleasant et al., 2017), issues related to care (Hobday et al., 2017; Pleasant et al., 2017; Ruiz et al., 2006), and issues related to management (Luconi, 2008; Rosen et al., 2002; Irvine et al., 2012; Rosen et al., 2002).

While there was little consistency in use of validated measures to assess intended outcomes, and while in some cases development of new measures was imperative, validation prior to measurement would have assisted in ensuring that the intended construct(s) were being 
measured. The duration of an intervention did not appear to affect outcomes as long as the intended information was conveyed (Banks et al., 2014; Broughton et al., 2011; Chao et al., 2016; Downs et al., 2006; Hobday et al., 2017; Irvine et al., 2012; Luconi et al., 2008; Pleasant et al., 2017; Rosen et al., 2002; Ruiz et al., 2006). Lastly, regardless of the intervention duration, all of the studies found a significant positive change in their outcomes, with an exception of two outcomes: change in participants' practice (Downs et al., 2006), and attitudes toward communication skills (Chao et al., 2016). Past research shows that changing practice is difficult (Berner et al., 2003; Sivananthan et al., 2013), and change in attitudes may require additional time or ongoing support and consultation to achieve (Hayes, 2003). Taking all of the evidence in consideration, the variety of educational material presentation, together with interactive nature of materials, was generally advantageous for learning and continued participation of healthcare professionals. 


\section{References}

Adler, G., Lawrence, B. M., Ounpraseuth, S. T., \& Asghar-Ali, A. A. (2015). A survey on dementia training needs among staff at community-based outpatient clinics.

Educational Gerontology, 41, 903-915. https://doi.org/10.1080/03601277.2015.1071549

Alushi, L., Hammond, J. A., \& Wood, J. H. (2015). Evaluation of dementia education programs for pre-registration healthcare students: A review of the literature. Nurse Education Today, 35, 992-998. https://doi.org/ 10.1016/j.nedt.2015.04.006.

Arribas-Marín, Hernández-Franco, and Plumed-Moreno. (2017). Nursing students' perception of academic support in the practicum: development of a reliable and valid measurement instrument. Journal of Professional Nursing, 33(5), 387-95. https://doi.org/ 10.1016/j.profnurs.2017.03.001

Arnautovska, U., Roleda, S., Jackson, J., \& Pachana, N. A. (2016). The knowledge and skills assessment (KASA) tool in the Australian dementia behavior management advisory service: development and initial testing. International Psychogeriatrics, 28, 833-844. https://doi.org/10.1017/S1041610215002070

Alzheimer Society of Canada. (2010). Rising tide: The impact of dementia on Canadian society. Retrieved from: http://www. alzheimer. ca/ /media/Files/national/ Advocacy/ASC_Rising\%20Tide-Executive\%20Summary_Eng.ashx.

Barrett, J. J, Haley W. E., Harrell, L. E., \& Powers, R. E. (1997). Knowledge about Alzheimer disease among primary care physicians, psychologists, nurse, and social workers. Alzheimer Disease and Associated Disorders, 11, 99-106. https://doi.org/10.1097/00002093-199706000-00006

Banks, P., Waugh A., Henderson J., Sharp B., Brown M., Oliver J., Marland G. (2014). 
Enriching the care of patients with dementia in acute settings? The dementia champions programme in Scotland. Dementia, 13(6). https://doi.org/10.1177/1471301213485084

Beeber, A. S., Zimmerman, S., Fletcher, S., Mitchell, C. M., \& Gould, E. (2010). Challenges and strategies for implementing and evaluating dementia care staff training in long-term care settings. Alzheimer's Care Today, 11(1), 17-39.

Berner, E.S., Baker, S., Funkhouser, E., Mehta, R.H., Eagle, K.A., Holmboe, E. (2003). Physician opinion leaders have limited influence on adherence to best-practice guidelines. Evidence-Based Healthcare, 7(3), 154-156.

Bandura, A. (1977). Social learning theory. Englewood Cliffs, N.J.: Prentice Hall.

Barrows, H. S. \& Feltovich, P. J. (1987). The clinical reasoning process. Medical Education, 21(2), 86-91.https://doi.org/10.1111/j.1365-2923.1987.tb00671.x

Boots, L. M. M., de Vught, M. E., van Knippenberg, R. J. M., Kempen, G. I. J., \& Verhey, F. R. J. (2013). A systematic review of internet-based supportive interventions for caregivers of patients with dementia. International Journal of Geriatric Psychiatry, 29, 331-344. https://doi.org/10.1002/gps.4016

Brody, A. A., \& Galvin, J. E. (2013). A review of interprofessional dissemination and education interventions for recognizing and managing dementia. Gerontology \& Geriatrics Education, 34, 225-256. https://doi.org/10.1080/02701960.2013.801342

Broughton, M., Smith, E. R., Baker, R., Angwin, A., Pachana, N., Copland, D. A.,...Chenery, H. J. (2011). Evaluation of a caregiver education program to support memory and communication in dementia: a controlled pretest-posttest study with nursing home staff. International Journal of Nursing Studies, 48, 1436-1444. https://doi.org/10.1016/j.ijnurstu.2011.05.007 
Bryans, M., Keady, J., Turner, S., Wilcock, J. (2003). An exploratory survey into primary care nurses and dementia care. British Journal of Nursing, 12, 1029-1037. https://doi.org/ 10.12968/bjon.2003.12.17.11723

Buhler, A. V., Farrell, M. K., Fuentes, D. G., Scott, B. J., Shaffer, K., \& Von, M. (2011). An interprofessional case conference on Alzheimer's disease: teaching students in the health professions to work together. Journal of Interprofessional Care, 25, 223-225. https://doi.org/10.3109/13561820.2011.552813

Canadian Academy of Health Sciences. (2019). Improving the quality of life and care of persons living with dementia and their caregivers. Ottawa (ON): The Expert Panel on Dementia Care in Canada, CAHS.

Cary, B. (2009). Pain, ageing and dementia: the crisis is looming, but are we ready? British Journal of Occupational Therapists, 72, 371-375.

Chao, H. C., Kaas, M., Su, Y. H., Lin, M. F., Huang, M. C., \& Wang, J. J. (2016). Effects of the advanced innovative internet-based communication education program on promoting communication between nurses and patients with dementia. Journal of Nursing Research, 24(2), 163-172. https://doi.org/10.1097/jnr.0000000000000109

Cobbett, S., Redmond, S., LeBlanc, A., MacNaughton-Doucet, L. J., Edgecombe, N., \& Helpard, H. (2016). On-line dementia education: cultivating nursing students' comprehension, application and critical thinking skills. Perspectives, 39, 9-14.

Cody, M., Beck, C., Shue, V. M., \& Pope, S. (2002). Reported practices of primary care physicians in the diagnosis and management of dementia. Aging and Mental Health, 6, 72-76. https://doi.org/10.1080/13607860120101158 
Coogle, C. L., Head, C. A., Parham, I. I., \& Zeman, S. (2004). Person-centered care and the workforce crisis: a statewide professional development initiative. Educational Gerontology, 30, 1-20. https://doi.org/10.1080/03601270490248428

Covidence [Computer program]. Version accessed 10 January 2017. Melbourne, Australia: Veritas Health Innovation. Available at www.covidence.org.

Critical Appraisal Skills Programme. (2014). CASP checklists. Retrieved from: http://www.caspuk.net/casp-tools-checklists

Degryse, J., De Lepeleire, J., Southgare, L., Vernooij-Dassen, M., Gay, B., \& Heyrman, J. (2009). An evaluation of a computer based education program for the diagnosis and management of dementia in primary care. An international study of the transcultural adaptations necessary for European dissemination. Medical Teacher, 31, 397-402. https://doi.org/10.1080/01421590802331438

Di Gregorio, D., Ferguson, S., \& Wiersma, E. (2015). From beginning to end: Perspectives of the dementia journey in northern Ontario. Canadian Journal on Aging, 34, 100-112. https://doi.org/10.1017/S0714980814000531

Downs, M., Turner, S., Bryans, M., Wilcock, J., Keady, J., Levin E.,...Iliffe, S. (2006). Effectiveness of educational interventions in improving detection and management of dementia in primary care: Cluster randomized controlled study. BMJ, 332(7543), 692696. https://doi.org/10.1136/bmj.332.7543.692

Eggenberger, E., Heimerl, K., \& Bennett, M. I. (2013). Communication skills training in dementia care: A systematic review of effectiveness, training content, and didactic methods in different care settings. International Psychogeriatrics, 25, 345-358. https://doi.org/10.1017/S1041610212001664 
Elliott, K.-E. J., Scott, J. L., Stirling, C., Martin, A. J., \& Robinson, A. (2012). Building capacity and resilience in the dementia care workforce: A systematic review of interventions targeting worker and organizational outcomes. International Psychogeriatrics, 24, 882894. https://doi.org/10.1017/S1041610211002651

Fahey-McCarthy, E., McCarron, M., Connaire, K., \& McCallion, P. (2009). Developing an education intervention for staff supporting persons with an intellectual disability and advanced dementia. Journal of Policy and Practice in Intellectual Disabilities, 6, $267-$ 275. https://doi.org/10.1111/j.1741-1130.2009.00231.x

Ferretti, M.T., Iulita, M. F., Cavedo, E., Chiesa, P. A., Dimech, A. S., Chadha, A. S.,...The Alzheimer Precision Medicine Initiative. (2018). Sex differences in Alzheimer diseasethe gateway to precision medicine. Nature Reviews Neurology, 14(8), 457-469. https://doi.org/10.1038/s41582-018-0032-9

Fishbein, M., \& Ajzen, I. (1975). Belief, attitude, intention, and behavior: An introduction to theory and research. Reading, MA: Addison-Wesley.

Fossey, J., Masson, S., Stafford, J., Lawrence, V., Corbett, A., \& Ballard, C. (2014). The disconnect between evidence and practice: A systematic review of person-centred interventions and training manuals for care home staff working with people with dementia. International Journal of Geriatric Psychiatry, 29, 797-807. https://doi.org/10.1002/gps.4072

Galvin, J. E., Meuser, T. M., Boise, L., \& Connell, C. (2011). Internet-based dementia resources: physician attitudes and practices. The Journal of Applied Gerontology, 30, 513-523. https://doi.org/10.1177/0733464810363894 
Gandesha (2012). Adequacy of training in dementia care for acute hospital staff. Nursing Older People, 24, 26-31. https://doi.org/10.7748/nop2012.05.24.4.26.c9070

Hallberg, I. R., Cabrera, E., Jolley, D., Raamat, K., Renom-Guiteras, A., Verbeek, H.,... Karlsson, S. (2016). Professional care providers in dementia care in eight European countries; their training and involvement in early dementia stage and in home care. Dementia, 15, 931-957. https://doi.org/10.1177/1471301214548520

Harvey, R. M., Hovarth, K. J., Levine, S. A., \& Volicer, L. (2006). Models of physical education for Alzheimer's Disease and dementia: Practical application in an integrated network. Clinical Gerontologist, 29, 11-23. https://doi.org/10.1300/J018v29n02_03

Hayes, D. (2003, August 21). Learning difficulties; consultation 'shows changing attitudes'. Community Care, 12. Retrieved from http://ink.galegroup.com/apps/doc/A106777593/GRGM?u=usaskmain\&sid=GRGM\&xi $d=562 b 39 c f$

Higgins, J. P. T., \& Green, S. (Eds). (2011). Cochrane Handbook for Systematic Reviews of Interventions Version 5.1.0 [updated March 2011]. The Cochrane Collaboration. Available from www.cochrane-handbook.org.

Hobday, J. V., Savik, K., Smith, S., \& Gaugler, J. E. (2010). Feasibility of internet training for care staff of residents with dementia: The CARES program. Journal of Gerontological Nursing, 36, 13-21. https://doi.org/10.3928/00989134-20100302-01

Hobday, J. V., Gaugler, J. E., \& Mittelman, M. S. (2017). Feasibility and utility of online dementia care training for hospital staff: The CARES ${ }^{\circledR}$ Dementia-Friendly Hospital $^{\mathrm{TM}}$ program. Research in Gerontological Nursing, 10(2), 58-65. https://doi.org/ $10.3928 / 19404921-20170131-01$ 
Innes, A., Szymczynska, P., \& Stark, C. (2015). Dementia diagnosis and post-diagnostic support in Scottish rural communities: Experiences of people with dementia and their families. Dementia, 13, 233-247. https://doi.org/10.1177/1471301212460608

Irvine, A. B., Ary, D. V., \& Bourgeois, M. S. (2003). An interactive multimedia program to train professional caregivers. The Journal of Applied Gerontology, 22, 269-288. https:// doi.org/10.1177/0733464803022002006

Irvine, A. B., Beaty, J. A., Seeley, J. R., \& Bourgeois, M. (2012). Use of a dementia training designed for nurse aides to train other staff. Journal of Applied Gerontology, 32(8), 936-951. https://doi.org/10.1177/073346481244602

Jones, C., \& Moyle, W. (2016). Sexuality \& dementia: An eLearning resource to improve knowledge and attitudes of aged-care staff. Educational Gerontology, 42, 563-571. https://doi.org/10.1080/03601277.2016.1205373

Jørgensen, A. W., Hilden, J., \& Gøtzsche, P. C. (2006). Cochrane reviews compared with industry supported meta-analyses and other meta-analyses of the same drugs: Systematic review. British Medical Journal, 333, 782-785. https://doi.org/10.1136/bmj.38973.444699.0B

Karpicke \& Smith (2012). Separate mnemonic effects of retrieval practice and elaborative encoding. Journal of Memory and Language, 67(1), 17-29

Knowles, M. (1984). Andragogy in action: Apply modern principle of adult education. San Francisco, CA: Jossey-Bass.

Kosteniuk, J. G., Morgan, D. G., O’Connell, M. E., Kirk, A., Crossley, M., Teare, G. T.,... Quail, J. M. (2016). Simultaneous temporal trends in dementia incidence and prevalence, 2005-2013: A population-based retrospective cohort study in Saskatchewan, Canada. 
International Psychogeriatrics, 28, 1643-1658.

https://doi.org/10.1017/S1041610216000818

Kosteniuk, J., Morgan, D., O’Connell, M. E., Dal Bello-Haas, V., \& Stewart, N. (2016). Focus on dementia care: Continuing education preferences, challenges, and catalysts among rural home care providers. Educational Gerontology, 42, 608-620. https://doi.org/ $10.1080 / 03601277.2016 .1205404$

Kuske, B., Hanns, S., Luck, T., Angermeyer, M. C., Behrens, J., \& Riedel-Heller, S. G. (2007). Nursing home staff training in dementia care: A systematic review of evaluated programs. International Psychogeriatrics, 19, 818-841. https://doi.org/10.1017/ S1041610206004352

Little, T. D. (2013). Longitudinal structural equation modeling. New York: Guilford Press.

Luconi, F. (2008). Exploring rural family physicians' learning from a web-based continuing medical education program on Alzheimer's disease: A pilot study (Doctoral dissertation). McGill University. Retrieved from: http://digitool.library.mcgill.ca/webclient/StreamGate?folder_id=0\&dvs=1534953144438 $\sim 185$

MacDonald, C. J., Stodel, E. J., \& Coulson, I. (2004). Planning an elearning dementia care program for healthcare teams in long-term care facilities: The learners' perspectives. Educational Gerontology, 30, 845-864. https://doi.org/10.1080/03601270490507295

Manthorpe, J., Iliffe, S., \& Eden, A. (2003). The implications of the early recognition of dementia for multiprofessional teamworking. Dementia, 2, 163-179. https://doi.org/ $10.1177 / 1471301203002002003$

Merkt, M., Weigand, S., Heier, A., \& Schwan, S. (2011). Learning with videos vs. learning with 
print: The role of interactive features. Learning and Instruction, 21, 687-704. https://doi.org/10.1016/j. learninstruc.2011.03.004

Mielke, M. M., Vemuri, P., Rocca, W. A. (2014). Clinical epidemiology of Alzheimer's disease: Assessing sex and gender differences. Clinical Epidemiology, 6, 37-48

Mitchell, A. J., Meader, \& Pentzek, M. (2011). Clinical recognition of dementia and cognitive impairment in primary care: A meta-analysis of physician accuracy. Acta Psychiatrica Scandinavica, 124, 165-183. https://doi.org/10.1111/j.1600-0447.2011.01730.x

Moher, D., Liberati, A., Tetzlaff, J., \& Altman, D. (2009). Reprint-Preferred reporting items for systematic reviews and meta-analyses: The PRISMA statement. American Physical Therapy Association, 89, 873-880. https://doi.org/10.7326/0003-4819-151-4-20090818000135

Moseley, A. M., Elkins, M. R., Herbert, R. D., Maher, C. G., \& Sherrington, C. (2009). Cochrane reviews used more rigorous methods than non-Cochrane reviews: Survey of systematic reviews in physiotherapy. Journal of Clinical Epidemiology, 62, 1021-1030. https://doi.org/10.1016/j.jclinepi.2008.09.018

Pleasant, M. L., Molinari, V., Hobday, J., Fazio, S., Cullen, N., Hyer, K. (2017). An evaluation of the CARES dementia basics program among caregivers. International Psychogeriatrics, 29, 45-56. https://doi.org/10.1017/S1041610216001526

Pitts, K., Pudney, K., Zachos, K., Maiden, N., Krogstie, B., Jones, D.,...Turner, I. (2015). Using mobile devices and apps to support reflective learning about older people with dementia. Behavior and Information Technology, 34, 613-631. https://doi.org/10.1080/0144929X.2015.1015165 
Podcasy, J. L., \& Epperson, C. N. (2016). Considering sex and gender in Alzheimer disease and other dementias. Dialogues of Clinical Neuroscience, 18(4), 437

Raymond, M., Warner, A., Davies, N., Baishnab, E., Manthorpe, J., \& Iliffe, S. (2014).

Evaluating educational initiatives to improve palliative care for people with dementia: A narrative review. Dementia, 13, 366-381. https://doi.org/10.1177/1471301212474140

Review Manager (RevMan) [Computer program]. Version 5.3. Copenhagen: The Nordic Cochrane Centre, The Cochrane Collaboration, 2014

Rokstad, A. M., Døble, B. S., Engedal, K., Kirkevold, Ø., Benth, J. Š., Selbaek, G. (2016). The impact of the dementia $\mathrm{ABC}$ educational programme on competence in person-centered dementia care and job satisfaction of care staff. International Journal of Older People Nursing, 12, 1-10. https://doi.org/10.1111/opn.12139

Rosen, J., Mulsant, B. H., Kollar, M., Kastango, K. B., Mazumdar, S., \& Fox, D. (2002). Mental health training for nursing home staff using computer-based interactive video: A 6-month randomized trial. Journal of the American Medical Directors Association, 3(5), 291-296. https://doi.org/10.1016/S1525-8610(05)70543-0

Ruiz, J. G., Smith, M., van Zuilen, M. H., Williams, C., \& Mintzer, M. J. (2006). The educational impact of a computer-based training tutorial on dementia in long-term care for licensed practice nursing students. Gerontology \& Geriatrics Education, 26, 67-79. https://doi.org/10.1300/J021v26n03_05

Scott, T. L, Mittelman. M. S., Beattie, E., Parker, D., \& Neville, C. (2015). Translating training in the NYU caregiver intervention in Australia: Maintaining fidelity and meeting graduate standards in an online continuing professional education setting. Educational Gerontology, 41, 710-722. https://doi.org/10.1080/03601277.2015.1048171 
Sizemore, M. T., Vicioso, B., Lothrop, J., \& Rubin, C. D. (1998). Outcome of a pilot dementia training program for primary care physicians. Educational Gerontology, 24, 27-34. https://doi.org/10.1080/0360127980240102

Sivananthan, S., Puyat, J., \& Mcgrail, K. (2013). Variations in self-reported practice of physicians providing clinical care to individuals with dementia: A systematic review. Journal of the American Geriatrics Society, 61(8), 1277-85. https://doi.org/ 10.1111 /jgs. 12368

Slotnick, H. B. (2001). How doctors learn: Physicians' self-directed learning episodes. Academic Medicine, 74(10), 1106-1113. https://doi.org/10.1097/00001888-199910000-00014

Spector, A., Orrell, M., \& Goyder, J. (2013). A systematic review of staff training interventions to reduce the behavioural and psychological symptoms of dementia. Ageing Research Reviews, 12, 354-364. https://doi.org/10.1016/j.arr.2012.06.005

Spector, A., Revolta, C., \& Orrell, M. (2016). The impact of staff training on staff outcomes in dementia care: A systematic review. International Journal of Geriatric Psychiatry, 31, 1172-1187. https://doi.org/10.1002/gps.4488

Stern, Y., Arenaza-Urquijo, E. M., Bartrés-Faz, D., Belleville, S., Cantilon, M., Chetelat, G.,...Vuoksimaa, E. (2018). Whitepaper: Defining and investigating cognitive reserve, brain reserve, and brain maintenance. Alzheimer's \& Dementia. https://doi.org/10.1016/j.jalz.2018.07.219

Surr, D. I., Gates, C., Irving, D., Oyebode, J., Smith, S. J., Parveen S.,...Dennison, A. (2017). Effective dementia education and training for the health and social care workforce: A systematic review of the literature. Review of Educational Research, 87(5), 966-1002. https://doi.org/10.3102/0034654317723305 
Waldorff, F. B., Siersma, V., Nielsen, B., Steenstrup, A. P., \& Bro, F. (2009). The effect of reminder letters on the uptake of an e-learning programme on dementia: A randomized trial in general practice. Oxford Journals, 26, 466-471. https://doi.org/10.1093/fampra/cmp072

Wood, J. M., Garb, H. N., Lilienfeld, S. O., \& Nezworski, M. T. (2002). Clinical Assessment. Annual Review of Psychology, 53, 519-543. https://doi.org/10.1146/annurev.psych.53.100901.135136 
Table 1. Adapted quality rating criteria for non-randomized controlled trial studies

\begin{tabular}{|c|c|c|c|}
\hline & Quality criteria & Specific questions relating to rating considerations & Rating \\
\hline & $\begin{array}{l}\text { Are the research } \\
\text { aims and } \\
\text { questions/hypotheses } \\
\text { clearly stated? }\end{array}$ & - Do(es) the author(s) clearly state what they plan to research? & $\begin{array}{l}0=\text { no } ; 1=\text { partially } ; \\
2=\text { yes }\end{array}$ \\
\hline & $\begin{array}{l}\text { Are ethical issues } \\
\text { addressed? }\end{array}$ & - Do(es) the author(s) state that ethical approval was sought? & $\begin{array}{l}0=\text { no; } 1=\text { partially } \\
2=\text { yes }\end{array}$ \\
\hline & $\begin{array}{l}\text { Are the } \\
\text { methodology/study } \\
\text { design appropriate to } \\
\text { the research question } \\
\text { and rationale for } \\
\text { choice evident? }\end{array}$ & $\begin{array}{l}\text { - Do(es) the author state what research methodology they have chosen? } \\
\text { - Is the chosen methodology appropriate to research question? } \\
\text { - Does the author(s) justify the research design used? }\end{array}$ & $\begin{array}{l}0=\text { no; } 1=\text { partially } \\
\text { but with } \\
\text { weaknesses/missing } \\
\text { info; } 2=\text { yes }\end{array}$ \\
\hline 4. & $\begin{array}{l}\text { Are the sample size, } \\
\text { selection and } \\
\text { description } \\
\text { appropriate? }\end{array}$ & $\begin{array}{l}\text { - Do(es) the author(s) clearly state how the study sample size was identified? } \\
\text { - Do(es) the sample size appear to be large enough? } \\
\text { Do(es) the author adequately describe the sample (e.g., gender, age, } \\
\text { relationship to care receiver) so that the reader can determine transferability } \\
\text { of findings? }\end{array}$ & $\begin{array}{l}0=\text { no; } 1=\text { partially } \\
\text { but with } \\
\text { weaknesses/missing } \\
\text { info; } 2=\text { yes }\end{array}$ \\
\hline & $\begin{array}{l}\text { Are the method(s) of } \\
\text { data collection } \\
\text { appropriate, reliable, } \\
\text { and valid? }\end{array}$ & $\begin{array}{l}\text { - Do(es) the author(s) justify that the measure is suitable for this population? } \\
\text { - Do(es) the author(s) use measures that measure the desired constructs? } \\
\text { - Do(es) the author(s) indicate that the measures have good psychometric } \\
\text { properties? } \\
\text { - Do(es) the author(s) indicate that the measures used have demonstrated } \\
\text { validity? }\end{array}$ & $\begin{array}{l}0=\text { no; } 1=\text { partially } \\
\text { but with } \\
\text { weaknesses/missing } \\
\text { info; } 2=\text { yes }\end{array}$ \\
\hline & $\begin{array}{l}\text { Are the method(s) of } \\
\text { data analysis reliable } \\
\text { and valid? }\end{array}$ & $\begin{array}{l}\text { - Do(es) the author(s) state which statistic tests were used? } \\
\text { - Do(es) the author(s) use statistical tests that appear to be appropriate to the } \\
\text { nature of the data collected? } \\
\text { - Were statistical tests appropriate to research question? } \\
\text { - Do(es) the author(s) provide evidence of statistical findings or state levels of } \\
\text { significance? }\end{array}$ & $\begin{array}{l}0=\text { no; } 1=\text { partially } \\
\text { but with } \\
\text { weaknesses/missing } \\
\text { info; } 2=\text { yes }\end{array}$ \\
\hline
\end{tabular}


7. Are the findings and discussion clearly stated and appropriate?

8. Can the results be applied to the local population?

9. Were all clinically important outcomes considered?
- Do(es) the author(s) present the statistical data in a clear manner, or clearly differentiate between significant or non-significant findings?

- How similar are the participants to the population to which the recommendations are applied?

- Was there other information about the outcomes which was missed?

te: $1-6=$ low range, $7-12=$ medium range, $13-18=$ high range
$0=$ no; $1=$ partially; $2=$ yes

$0=$ no; $1=$ partially; $2=$ yes

$0=$ no; $1=$ partially; $2=$ yes

Range: 0-18 
Table 2. Adapted quality rating criteria for randomized controlled trial studies

\begin{tabular}{|c|c|c|c|}
\hline & Quality criteria & Specific questions relating to rating considerations & Rating \\
\hline & $\begin{array}{l}\text { Did the research } \\
\text { question clearly } \\
\text { address a focused } \\
\text { issue? }\end{array}$ & $\begin{array}{l}\text { - Was the research question focused on the target population, and the } \\
\text { intervention? } \\
\text { - Were outcomes in research considered? }\end{array}$ & $\begin{array}{l}0=\text { no; } 1=\text { partially; } \\
2=\text { yes }\end{array}$ \\
\hline 2. & $\begin{array}{l}\text { Was the assignment } \\
\text { of participants } \\
\text { randomized to the } \\
\text { intervention or the } \\
\text { control group? }\end{array}$ & $\begin{array}{l}\text { - How was randomization achieved? } \\
\text { - Was randomization concealed from researcher or participants? }\end{array}$ & $\begin{array}{l}0=\text { no; } 1=\text { partially; } \\
2=\text { yes }\end{array}$ \\
\hline 3. & $\begin{array}{l}\text { Were all of the } \\
\text { participants } \\
\text { properly accounted } \\
\text { for at the } \\
\text { conclusion of the } \\
\text { intervention? }\end{array}$ & - Were the participants analyzed in groups to which they were randomized? & $\begin{array}{l}0=\text { no; } 1=\text { partially; } \\
2=\text { yes }\end{array}$ \\
\hline 4. & $\begin{array}{l}\text { Were participants, } \\
\text { and care recipients } \\
\text { blind to whether } \\
\text { they were in the } \\
\text { intervention or the } \\
\text { control group? }\end{array}$ & $\begin{array}{l}\text { - Consider reporting of participant blinding to intervention/control, and blinding } \\
\text { of researcher(s) to condition in assessment of outcomes. }\end{array}$ & $\begin{array}{l}0=\text { no; } 1=\text { partially; } \\
2=\text { yes }\end{array}$ \\
\hline 5. & $\begin{array}{l}\text { Were the } \\
\text { intervention and } \\
\text { control groups } \\
\text { similar at the start } \\
\text { of the study? }\end{array}$ & $\begin{array}{l}\text { - Were the intervention and control groups similar in terms of their age, sex, } \\
\text { social class...etc? }\end{array}$ & $\begin{array}{l}0=\text { no; } 1=\text { partially; } \\
2=\text { yes }\end{array}$ \\
\hline 6. & $\begin{array}{l}\text { Aside from the } \\
\text { intervention group, } \\
\text { where the } \\
\text { intervention and }\end{array}$ & - Here also consider duration of intervention or placebo. & $\begin{array}{l}0=\text { no; } 1=\text { partially; } \\
2=\text { yes }\end{array}$ \\
\hline
\end{tabular}


control groups

treated equally?

7. How large was the treatment effect?

- Was/were the primary outcome(s) clearly stated?

- What were the results for each outcome?

8. How precise was the estimate of the treatment effect?

9. Can the results be applied to the local population?

10. Were all clinically important outcomes considered?

11. Are benefits worth the harms and

- What were the confidence limits? costs?

- How similar were the participants to the population to which the recommendations were applied?

- Was there other information about the outcomes that was missed?

- Here consider possibility of harm in the control condition, if education piece was missed.
$0=$ no; $1=$ partially;

$2=$ yes

$0=$ no; $1=$ partially;

$2=$ yes

$0=$ no; $1=$ partially;

$2=$ yes

$0=$ no; $1=$ partially;

$2=$ yes

$0=$ no $; 1=$ partially;

$2=$ yes

Range: 0-21

Note: $1-7=$ low range, $7-15=$ medium range, $16-21=$ high range 
Table 3. Studies included in the review $(N=10)$

\begin{tabular}{|c|c|c|c|c|c|}
\hline Author, year & Theoretical model & $\begin{array}{l}\text { Design, sample size, } \\
\text { attrition, female }(\%)\end{array}$ & $\begin{array}{l}\text { Duration of type of } \\
\text { intervention }\end{array}$ & Follow-up & Outcome scales \\
\hline Chao, 2016 & Adult Learning Theory & $\begin{array}{l}\text { QEWPP, } n=105, n \\
=2, \text { Female: } 100 \%\end{array}$ & $\begin{array}{l}16 \text { weeks; } 4 \\
\text { learning modules: } \\
\text { modules } 1 \text { and } 2,4 \\
\text { hour classroom } \\
\text { lectures and } \\
\text { workshop, modules } \\
3 \text { and } 4 \text { online } \\
\text { modules }\end{array}$ & $\begin{array}{l}\text { Week 4, } \\
\text { week } 16\end{array}$ & $\begin{array}{l}\text { CKS-C, CSAS-C, } \\
\text { PREAS }\end{array}$ \\
\hline Hobday, 2017 & $\begin{array}{l}\text { The CARES }{ }^{\mathrm{TM}} \text { Dementia- } \\
\text { Friendly Hospital Program } \\
\text { Learning Principles }\end{array}$ & $\begin{array}{l}\text { WSPP, } n=25, n= \\
\text { NA, Female: } 96 \%\end{array}$ & $\begin{array}{l}7 \text { to } 10 \text { days; } 4 \\
\text { online learning } \\
\text { modules, } 15-20 \\
\text { minutes in duration }\end{array}$ & $\begin{array}{l}\text { Baseline, } 10 \\
\text { days }\end{array}$ & $\begin{array}{l}\text { Dementia } \\
\text { Knowledge Scale }\end{array}$ \\
\hline Irvine, 2012 & $\begin{array}{l}\text { Social Cognitive Theory, } \\
\text { Expanded Theory of Reasoned } \\
\text { Action }\end{array}$ & $\begin{array}{l}\text { WSPP, } n=57, n= \\
11 \text {, Female: } 85.9 \%\end{array}$ & $\begin{array}{l}2 \text { hours total, self- } \\
\text { paced; } 5 \text { modules } \\
\text { available via work } \\
\text { web-site }\end{array}$ & $\begin{array}{l}\text { Baseline, } 14 \\
\text { days, } 30 \\
\text { days }\end{array}$ & $\begin{array}{l}\text { Video Situation } \\
\text { Test: attitudes, self- } \\
\text { efficacy, behavioral } \\
\text { intentions }\end{array}$ \\
\hline Ruiz, 2006 & No model & $\begin{array}{l}\text { WSPP, } n=38, n= \\
\text { NA, Female: } 89 \%\end{array}$ & $\begin{array}{l}2 \text { days, } 7 \text { modules, } \\
\text { each } 20-30 \\
\text { minutes, } \\
\text { administered via } \\
\text { CD-Rom in } \\
\text { computer lab }\end{array}$ & $\begin{array}{l}\text { Baseline, } \\
\text { post } \\
\text { intervention }\end{array}$ & $\begin{array}{l}\text { Dementia } \\
\text { knowledge, Self- } \\
\text { perceived efficacy }\end{array}$ \\
\hline Banks, 2014 & No model & $\begin{array}{l}\mathrm{PP}, n=113, n=\mathrm{NA}, \\
\text { Female: NA }\end{array}$ & $\begin{array}{l}5 \text { months, online } \\
\text { learning modules } \\
\text { completed prior to } \\
\text { study/community } \\
\text { setting days }\end{array}$ & $\begin{array}{l}\text { Baseline, } \\
\text { post } \\
\text { intervention }\end{array}$ & ADS, Self-efficacy \\
\hline Pleasant, 2017 & $\begin{array}{l}\text { CARES }{ }^{\mathrm{TM}} \text { Dementia Basics } \\
\text { Program Principles }\end{array}$ & $\begin{array}{l}\text { PP, } n=51, n=11, \\
\text { Female: } 88 \%\end{array}$ & $\begin{array}{l}2 \text { weeks, } 4 \text { online } \\
\text { learning modules, }\end{array}$ & $\begin{array}{l}\text { Baseline, } \\
\text { post }\end{array}$ & DKQ, SCIDS \\
\hline
\end{tabular}




\begin{tabular}{|c|c|c|c|c|c|}
\hline Luconi, 2008 & $\begin{array}{l}\text { Cognitive Constructivism } \\
\text { Theory, Socio-Constructivism, } \\
\text { Four-Stage Theory of } \\
\text { Physician's Learning, Clinical } \\
\text { Reasoning } \\
\text { Model }\end{array}$ & $\begin{array}{l}\mathrm{CS}, n=8, n=\mathrm{NA} \\
\text { Female: } 38 \%\end{array}$ & $\begin{array}{l}40 \text { minutes in } \\
\text { duration } \\
14 \text { hours, over } 9 \\
\text { months, } 7 \text { online } \\
\text { modules, each } 3 \\
\text { hours in duration }\end{array}$ & $\begin{array}{l}\text { intervention, } \\
30 \text { days } \\
\text { Baseline, } 6 \\
\text { month }\end{array}$ & PRQ, Barometer \\
\hline $\begin{array}{l}\text { Broughton, } \\
2011\end{array}$ & No model & $\begin{array}{l}\mathrm{RCT}, n=34 \\
\text { (training group), } n= \\
15 \text { (control group), } n \\
=3, \text { Female: } 86.5 \%\end{array}$ & $\begin{array}{l}\text { Training DVD, } 50 \\
\text { minutes }\end{array}$ & $\begin{array}{l}\text { Baseline, } \\
\text { post } \\
\text { intervention, } \\
3 \text { months }\end{array}$ & $\begin{array}{l}\text { PAC, Caregiver } \\
\text { Satisfaction } \\
\text { Questionnaire }\end{array}$ \\
\hline Downs, 2006 & No model & $\begin{array}{l}\mathrm{RCT}, n=9 \\
\text { (practice-based } \\
\text { workshop), } n=8 \\
\text { (electronic tutorial), } \\
n=8 \text { (decision-based } \\
\text { software), } n=10 \\
\text { (control), } n=1, \\
\text { Female: } 79.4 \%\end{array}$ & $\begin{array}{l}12 \text { months, } \\
\text { electronic tutorial } \\
\text { available on a CD- } \\
\text { Rom, integrated in } \\
\text { electronic patient } \\
\text { files }\end{array}$ & $\begin{array}{l}\text { Baseline, } \\
\text { post } \\
\text { intervention }\end{array}$ & $\begin{array}{l}\text { Dementia diagnosis } \\
\text { concordance, } \\
\text { dementia } \\
\text { management } \\
\text { concordance }\end{array}$ \\
\hline Rosen, 2002 & No model & $\begin{array}{l}\mathrm{RCT}, n=103 \\
(\text { Lecture site, attrition } \\
=15 \%), n=70 \\
\text { (Computer-based } \\
\text { training, attrition }= \\
26 \%), n=106 \\
\text { (control, attrition = } \\
26 \%), \text { Female: NA }\end{array}$ & $\begin{array}{l}6 \text { months, } 12 \\
\text { computer-based } \\
\text { interactive video } \\
\text { training modules }\end{array}$ & $\begin{array}{l}\text { Baseline, } \\
\text { post } \\
\text { intervention }\end{array}$ & $\begin{array}{l}\text { Dementia } \\
\text { knowledge }\end{array}$ \\
\hline
\end{tabular}

Note: $\mathrm{RCT}=$ randomized controlled trial, QEWPP $=$ quasi-experimental with pre- and post- measures, WSPP $=$ within subjects with pre- and post- measures, $\mathrm{PP}=$ pre- and post- measures, $\mathrm{CS}=$ controlled case study, $\mathrm{NA}=$ not available, $\mathrm{CKS}-\mathrm{C}=\mathrm{Communication}$ 
Knowledge Scale - Chinese version, CSAS-C = Skills and Attitudes Scale- Chinese version, PREAS = Patient's Receptive and Expressive Ability Scale, ADS = Approaches to Dementia Scale, CCS = Communication Competency Scale, CPS $=$ Communication Performance Scale, DKQ = Dementia Knowledge Questionnaire, SCIDCS = Sense of Competence in Dementia Care- Staff Scale, PRQ-I = Participant Reaction Questionnaire, PAC = Positive Aspects of Care giving. 
Table 4. Characteristics of included studies $(N=10)$

\begin{tabular}{|c|c|}
\hline Description & $\mathrm{N}(\%)$ \\
\hline \multicolumn{2}{|l|}{ Country of study } \\
\hline United States & $5(50)$ \\
\hline United Kingdom & $1(10)$ \\
\hline Canada & $1(10)$ \\
\hline Australia & $1(10)$ \\
\hline Scotland & $1(10)$ \\
\hline Taiwan & $1(10)$ \\
\hline \multicolumn{2}{|l|}{ Health professionals ${ }^{\mathrm{a}}$} \\
\hline Nurses & $5(50)$ \\
\hline Licensed practical nurses & $1(10)$ \\
\hline Certified nursing assistants & $2(20)$ \\
\hline Non-direct care staff & $1(10)$ \\
\hline Family physicians & $2(20)$ \\
\hline Recreational activity officers & $2(20)$ \\
\hline Dieticians & $1(10)$ \\
\hline Occupational therapists & $1(10)$ \\
\hline Physiotherapists & $1(10)$ \\
\hline Speech and Language Pathologists & $1(10)$ \\
\hline Managers & $1(10)$ \\
\hline Volunteers & $1(10)$ \\
\hline Allied health professionals & $1(10)$ \\
\hline \multicolumn{2}{|l|}{ Setting } \\
\hline Long-term care & $2(20)$ \\
\hline Nursing home & $1(10)$ \\
\hline General practice & $2(20)$ \\
\hline $\begin{array}{l}\text { Secondary education/professional } \\
\text { development }\end{array}$ & $2(20)$ \\
\hline Primary care & $1(10)$ \\
\hline Acute care & $1(10)$ \\
\hline Hospital & $1(10)$ \\
\hline \multicolumn{2}{|l|}{ Location } \\
\hline Urban & $0(0)$ \\
\hline Rural & $1(10)$ \\
\hline Unknown & $9(90)$ \\
\hline \multicolumn{2}{|l|}{ Study Quality } \\
\hline High & $8(80)$ \\
\hline Medium & $2(20)$ \\
\hline Low & $0(0)$ \\
\hline
\end{tabular}

${ }^{a}$ Number of health professionals is greater, since some of the studies used multiple types of health professionals in their interventions. 
Table 5. Risk of bias assessment $(N=10)$

\begin{tabular}{|c|c|c|c|c|c|c|c|}
\hline $\begin{array}{l}\text { Author, } \\
\text { year }\end{array}$ & $\begin{array}{l}\text { Type } \\
\text { of } \\
\text { study }\end{array}$ & $\begin{array}{l}\text { Random } \\
\text { sequence } \\
\text { generatio } \\
\mathrm{n}\end{array}$ & $\begin{array}{l}\text { Allocation } \\
\text { concealme } \\
\mathrm{nt}\end{array}$ & $\begin{array}{l}\text { Blinding } \\
\text { of } \\
\text { participant } \\
\text { s }\end{array}$ & $\begin{array}{l}\text { Blinding } \\
\text { of } \\
\text { outcome } \\
\text { assessme } \\
\text { nt }\end{array}$ & $\begin{array}{l}\text { Incomplet } \\
\text { e outcome } \\
\text { data }\end{array}$ & $\begin{array}{l}\text { Selectiv } \\
\mathrm{e} \\
\text { reportin } \\
\mathrm{g}\end{array}$ \\
\hline $\begin{array}{l}\text { Chao, } \\
2016\end{array}$ & $\begin{array}{l}\text { Pre/Pos } \\
t\end{array}$ & $?$ & $?$ & $?$ & $?$ & - & - \\
\hline $\begin{array}{l}\text { Hobday, } \\
2017\end{array}$ & $\begin{array}{l}\text { Pre/Pos } \\
\mathrm{t}\end{array}$ & $?$ & $?$ & $?$ & $?$ & + & - \\
\hline $\begin{array}{l}\text { Irvine, } \\
2012\end{array}$ & $\begin{array}{l}\text { Pre/Pos } \\
\mathrm{t}\end{array}$ & ? & ? & ? & $?$ & + & - \\
\hline $\begin{array}{l}\text { Ruiz, } \\
2006\end{array}$ & $\begin{array}{l}\text { Pre/Pos } \\
t\end{array}$ & $?$ & $?$ & $?$ & $?$ & - & - \\
\hline $\begin{array}{l}\text { Banks, } \\
2014\end{array}$ & $\begin{array}{l}\text { Pre/Pos } \\
t\end{array}$ & $?$ & $?$ & $?$ & $?$ & - & - \\
\hline $\begin{array}{l}\text { Pleasant, } \\
2017\end{array}$ & $\begin{array}{l}\text { Pre/Pos } \\
t\end{array}$ & $?$ & $?$ & $?$ & $?$ & - & - \\
\hline $\begin{array}{l}\text { Luconi, } \\
2008\end{array}$ & $\begin{array}{l}\text { Pre/Pos } \\
\mathrm{t}\end{array}$ & $?$ & $?$ & ? & $?$ & + & - \\
\hline $\begin{array}{l}\text { Broughto } \\
\text { n, } 2011\end{array}$ & RCT & ? & - & - & $?$ & + & - \\
\hline $\begin{array}{l}\text { Downs, } \\
2006\end{array}$ & $\mathrm{RCT}$ & - & - & - & $?$ & - & - \\
\hline $\begin{array}{l}\text { Rosen, } \\
2002\end{array}$ & $\mathrm{RCT}$ & $?$ & $?$ & $?$ & $?$ & + & - \\
\hline
\end{tabular}


Table 6. Teaching and learning approaches $(N=10)$

\begin{tabular}{lr}
\hline Teaching/learning approaches & $N(\%)$ \\
\hline Computer-based learning & $100(100)$ \\
Learning via alternate mediums & $2(20)$ \\
$\quad$ CD-Rom & $1(10)$ \\
DVD & $7(70)$ \\
Learning with an online component & $2(20)$ \\
Learning with an online and a face-to-face & \\
component & $2(20)$ \\
Access via a moderated platform & $2(20)$ \\
Video-based learning & $4(40)$ \\
$\quad$ Video scenarios & $1(10)$ \\
$\quad$ Video modeling vignettes & \\
$\quad$ Videos featuring unscripted & $2(20)$ \\
$\quad$ interactions (patients, staff, caregivers) & $2(20)$ \\
Videos featuring expert commentary & $1(10)$ \\
Case studies & $2(20)$ \\
Interviews with staff members & $1(10)$ \\
Audio-narration & $2(20)$ \\
Interactive text entry & $1(10)$ \\
Discussion board & $1(10)$ \\
Moderated discussion board & $1(10)$ \\
Quizzes with automatic feedback & $1(10)$ \\
Course email/calendar & \\
Technical assistance help function &
\end{tabular}


Table 7. Classification of statistically significant outcomes by scales

\begin{tabular}{|c|c|c|c|c|c|c|c|c|c|c|}
\hline \multirow[t]{2}{*}{ Outcome, scales } & \multicolumn{4}{|c|}{ Dementia education available online } & \multicolumn{3}{|c|}{$\begin{array}{l}\text { Dementia education available via } \\
\text { alternate mode(s) }\end{array}$} & \multicolumn{3}{|c|}{$\begin{array}{l}\text { Dementia education with an } \\
\text { applied component or requiring } \\
\text { in-person presence }\end{array}$} \\
\hline & $\begin{array}{l}\text { Rosen, } \\
2002\end{array}$ & $\begin{array}{l}\text { Luconi, } \\
2008\end{array}$ & $\begin{array}{l}\text { Pleasant, } \\
2017\end{array}$ & $\begin{array}{l}\text { Hobday, } \\
2017\end{array}$ & $\begin{array}{l}\text { Downs, } \\
2006\end{array}$ & $\begin{array}{l}\text { Broughton, } \\
2011\end{array}$ & $\begin{array}{l}\text { Irvine, } \\
2012\end{array}$ & $\begin{array}{l}\text { Banks, } \\
2014\end{array}$ & $\begin{array}{l}\text { Ruiz, } \\
2006\end{array}$ & $\begin{array}{l}\text { Chao, } \\
2016\end{array}$ \\
\hline \multicolumn{11}{|c|}{$\begin{array}{l}\text { Dementia general } \\
\text { knowledge }\end{array}$} \\
\hline $\begin{array}{l}\text { Dementia } \\
\text { diagnostic } \\
\text { knowledge } \\
\text { DKQ }\end{array}$ & $++^{b}$ & & + & & & & & & $++^{b}$ & \\
\hline $\begin{array}{l}\text { Diagnosis } \\
\text { concordance }\end{array}$ & & & & & $+^{\mathrm{b}}$ & & & & & \\
\hline \multicolumn{11}{|c|}{ Dementia care/management knowledge } \\
\hline $\begin{array}{l}\text { Management } \\
\text { concordance } \\
\text { Dementia Care } \\
\text { Knowledge Scale }\end{array}$ & & & & $+\mathrm{b}$ & $0^{\mathrm{b}}$ & & & & & \\
\hline \multicolumn{11}{|c|}{ Readiness to change } \\
\hline $\begin{array}{l}\text { Video Situation } \\
\text { Test- Behavioral } \\
\text { Intentions }\end{array}$ & & & & & & & $+^{\mathrm{b}}$ & & & \\
\hline \multicolumn{11}{|c|}{ Reaction to training } \\
\hline PRQ-I & & $++^{b}$ & & & & & & & & \\
\hline $\begin{array}{l}\text { Barometer- } \\
\text { Readiness to } \\
\text { Learn }\end{array}$ & & $++^{\mathrm{b}}$ & & & & & & & & \\
\hline \multicolumn{11}{|l|}{ Care strategies } \\
\hline ADS & & & & & & & & + & & \\
\hline
\end{tabular}




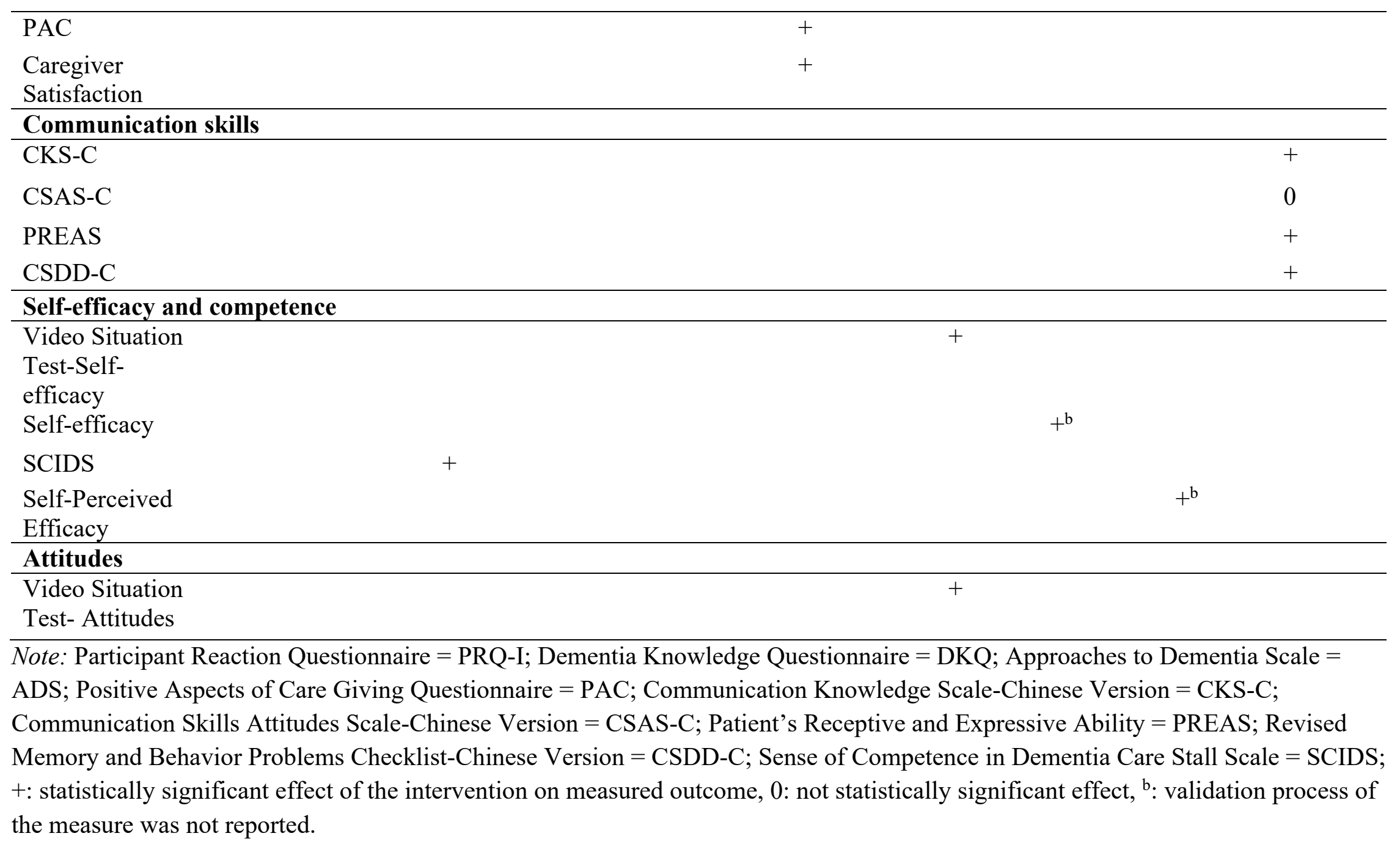




\section{Appendix}

PsycINFO MeSH terms and keywords logic grid

\begin{tabular}{|c|c|c|}
\hline $\begin{array}{l}\text { caregivers OR (care provid\$3 } \\
\text { OR care partner OR family } \\
\text { care\$6 OR family care } \\
\text { partner OR family care } \\
\text { provider OR familial care OR } \\
\text { family carer OR informal } \\
\text { carer OR primary caregiv } \$ 2 \\
\text { OR child caregiv\$ OR spouse } \\
\text { caregiv\$ OR informal } \\
\text { caregiver OR informal } \\
\text { caregiv\$).mp }\end{array}$ & $\begin{array}{l}\text { dementia OR Alzheimer's } \\
\text { disease OR Parkinson's } \\
\text { disease OR vascular dementia } \\
\text { OR dementia with Lewy } \\
\text { bodies OR semantic dementia } \\
\text { OR neurodegenerative } \\
\text { diseases OR cognitive } \\
\text { impairment OR } \\
\text { neurodegeneration OR } \\
\text { (frontotemporal dementia OR } \\
\text { early onset dementia OR } \\
\text { young onset dementia OR } \\
\text { late onset dementia OR mild } \\
\text { cognitive impairment OR late } \\
\text { elderly dementia).mp }\end{array}$ & $\begin{array}{l}\text { online education OR } \\
\text { computer assisted instruction } \\
\text { OR distance education OR } \\
\text { internet OR computer } \\
\text { applications OR computer } \\
\text { searching OR computer } \\
\text { training OR technology OR } \\
\text { machine learning OR virtual } \\
\text { classrooms OR multimedia } \\
\text { OR websites OR electronic } \\
\text { learning OR mobile devices } \\
\text { OR telemedicine OR } \\
\text { teleconferencing OR } \\
\text { videotape instruction OR } \\
\text { telecommunications media } \\
\text { OR telephone systems OR } \\
\text { (online learning OR online } \\
\text { training OR online program } \\
\text { OR online tool OR online } \\
\text { resources OR computer-based } \\
\text { OR computerized OR } \\
\text { asynchronous OR portal OR } \\
\text { learning application OR } \\
\text { videoconferencing OR } \\
\text { telephone-based OR } \\
\text { telephone-delivered).mp }\end{array}$ \\
\hline
\end{tabular}

